\title{
Alkaline Hydrogen Peroxide Pretreatment of AÇaí SEEDS WASTE (ASW) FOR FERMENTABLE SUGARS AND ETHANOL PRODUCTION
}

\author{
Johnatt Allan Rocha de Oliveira ${ }^{1}$, Marcele Fonseca Passos ${ }^{2}$, \\ Adriene Carvalho da Conceição ${ }^{3}$ \\ ${ }^{1}$ Department of nutrition, Federal University of Pará, Belém, Pará, Brazil, zipcode 66075-110 \\ johnattrocha@yahoo.com.br \\ ${ }^{2}$ Department of Biotechnology, Federal University of Pará, Belém, Pará, Brazil \\ Marcelepassos2004@yahoo.com.br \\ ${ }^{3}$ Department of nutrition, Federal University of Pará, Belém, Pará, Brazil \\ adrienecarvalho18@gmail.com
}

\begin{abstract}
The possibility of converting lignocellulosic waste into ethanol and sugars is commercial and environmentally interesting, since both are the basis for countless materials for chemical use. The objective of this work was to evaluate the pre-treatment with alkaline hydrogen peroxide (AHP) of the açai seeds for production of fermentable sugars and ethanol. A full factorial design $3^{(2-0)}$ was carried out with the variables: pre-treatment temperature $\left(25-60^{\circ} \mathrm{C}\right)$ and concentration of alkaline hydrogen peroxide $(4-10 \%)$. The pre-treated material was hydrolysed with 15 FPU/g of Celluclast 1.5 L from Trichoderma reesei and the released glucose levels were measured. The best pre-treatment condition ( $4 \%$ peroxide at $4 \%$ at $60^{\circ} \mathrm{C}$ for $60 \mathrm{~min}$.) was used to produce enzymatic hydrolysates that were fermented in Erlenmeyer and reactor/fermenter, and the ethanol and glucose yields were analysed on HPLC. The highest glucose yield found was $5.95 \mathrm{~g} . \mathrm{L}^{-1}$; and the maximum yields of ethanol in the fermentation were 2,41 g. $L^{-1}$ in Erlenmeyer and 2,69 g. $L^{-1}$ in the reactor/fermenter. The volumetric ethanol production rate were 0.10 and $0.11 g . L^{-1} \cdot h^{-1}$.
\end{abstract}

KEYWORDS: ethanol production, açaí seeds, glucose production, biomass, enzymatic hydrolysis

\section{INTRODUCTION}

Brazil stands out when it comes to biofuels, with more than 35 years of research into the production and use of ethanol. However, many critics are made about the production of Brazilian ethanol, since for some it generates pressure on the price of food and impact on forest cover [1].

To reduce these possible impacts, lignocellulosic materials, consisting of cellulose, hemicellulose and lignin, are alternatives for ethanol production. This material has a great variety and quantity in Brazil, varying according to region, for instance, in the Northern of Brazil where acai seeds are often classified as garbage, and which constitutes a huge inconvenience to the health and hygiene of the most important cities in this region, such as Belém and Manaus. Thus, the possibility of converting açaí seed waste in ethanol after the process of obtaining the açaí juice, would be interesting from the commercial point of view, since it contributes to the techno-economic and environmental development in the northern cities of Brazil [2].

There is great interest not only in ethanol but also in the sugars produced during the stages of using biomass (mainly glucose and xylose). The development of the bio-based industry has increased interest in products such as ethanol, aldehydes, organic acids, polyhydric alcohols and other biochemicals and biomaterials [3]. Sugars, the most important intermediate compounds in the biological and chemical transformation of biomass, are crucial for the production of chemicals of industrial interest $[4,5]$.

According to the Brazilian Institute of Geography and Statistics [6], in Brazil about 216,071 tons of açaí were produced in 2016, with the largest producer being State of Pará, with 61.2\% of the total, of 
which 188,702 tons are discarded such as waste (seeds), which are disposed of in landfills and waterways.

Lignocellulosic materials from agroindustrial waste and plant extracts are the most abundant renewable organic resources on earth and because of this they have been used in large scale to generate energy, for example through the production of second generation ethanol obtained by hydrolysis of the polysaccharides present in the cell wall [7]. The acai seeds is composed of cellulose, hemicellulose and lignin, thus a lignocellulosic biomass, which, because it has large amounts of cellulose, hemicellulose (63.5\%), is a source of carbon for the fermentation and production of ethanol [2]. In this way, it is possible to transform a raw material of low cost and renewable origin, such as açaí seeds waste, into a high added value product, such as ethanol.

Although the main biomass used for the production of ethanol in Brazil is sugar cane, some regions of the country are not producers of such a vegetable, similar to what happens with other countries in the world, which have ethanol produced from other biomasses, corn and beet [8,9]. Some regions of Brazil, the northern region, need to find alternative raw materials to be used for the production of ethanol, such as açaí seeds, which have already demonstrated high amounts of cellulose and thus great potential for ethanol production, this could even reduce future costs related to the transportation of sugarcane ethanol between the two Brazilian regions mentioned.

For ethanol production from lignocellulosic materials is necessary that the biomass pass by important steps, which are: pre-treatment, enzymatic hydrolysis and fermentation [10]. The more detailed knowledge of these steps in specific materials has a huge importance, since different materials will present different behaviours during the stages of ethanol production.

Alkaline Hydrogen peroxide pretreatment is traditionally employed in papermaking industry as a bleaching method and is one of the most promising methods for lignocellulosic biomass to remove lignin from this material [11]. The evaluation of alkaline hydrogen peroxide pretreatment and subsequent enzymatic hydrolysis constitutes an important study for ethanol production, adding value to açaí supply chain in Brazil. Thus, the aim of this work was to evaluate the Alkaline Hydrogen peroxide pretreatment for sugar and ethanol production from the açaí seeds.

\section{Material AND MethodS}

\subsection{Raw material}

The açaí seeds were obtained in Belém - Pará - Brazil (01 $\left.27^{\circ} 21^{\prime \prime} \mathrm{S}, 48^{\circ} 30^{\prime} 16^{\prime \prime} \mathrm{W}\right)$ and material was prepared according to Oliveira et al. [12]. The material were dried for $48 \mathrm{~h}$ at $50^{\circ} \mathrm{C}$ in an air circulating oven and left for $48 \mathrm{~h}$ at room temperature. The material was crushed in a knife mill of the Willye model TE-650 - Tecnal - Brazil and sieved. The material used was the one that passed through the 9 mesh sieve $(2.0 \mathrm{~mm})$ and was retained in the 35 mesh sieve $(0.43 \mathrm{~mm})$.

\subsection{Chemical Composition}

The moisture content was determined following the NREL standard for Determination of Total Solids in Biomasses [13]. For this, petri dishes were used, where 2 grams of the crushed sample were weighed and heated to $105^{\circ} \mathrm{C}$, where they remained for 8 hours until constant weight [13]. The ash content was obtained by gravimetric method by calcination of the pre-incinerated crushed porcelain crucible sample at $550^{\circ} \mathrm{C}$ in a muffle for 4 hours according to AOAC method No. 940.26 [14]. The determination of extractives was based on NREL $\mathrm{n}^{\circ} 10$, "Determination of Extractives in Biomass" [15] This analysis was subdivided into two stages of extraction in the Soxhlet extractor. The untreated and pretreated seeds of açaí were analyzed for carbohydrate and lignin (acid-soluble and insoluble) according to the method presented by Sluiter et al. [15]. The total lignin was calculated by the sum of Klason lignin and acidsoluble lignin. The amount of acid-insoluble lignin was determined by the Klason method [16] and the soluble lignin concentration was determined by measuring absorbance at $280 \mathrm{~nm}$ and using the value of $105 \mathrm{~L} \cdot \mathrm{g}^{-1} \cdot \mathrm{cm}^{-1}$ as the absorptivity of soluble lignin. The concentrations of monomeric sugars in the soluble fraction were determined by high performance liquid chromatography (HPLC) after acid hydrolysis with $\mathrm{H}_{2} \mathrm{SO}_{4} 72 \%$ (the resultant liquor was used to soluble lignin determination). 


\subsection{HPLC analysis}

The released sugar monomers in this work were determined by HPLC (Agilent) using a column (BioRad Aminex HPX-87H, $300 \times 7.8 \mathrm{~mm}$ ) at $35^{\circ} \mathrm{C}$ and $4 \mathrm{mM} \mathrm{H}_{2} \mathrm{SO}_{4}$ as eluent at a flow rate of $0.6 \mathrm{~mL} \mathrm{~min}^{-1}$ injected sample volume $25 \mu \mathrm{m}$ through of the detector RI (refractive index). For ethanol produced in fermentation, the fraction resulting from the centrifugation of the fermented material was diluted and filtered, with syringes coupled to filters containing cellulose ester micropore $(0.22 \mu \mathrm{m}$ pore diameter $)$ and analyzed. For this, the Agilent Technologies 1260 Infinity HPLC liquid chromatograph with IR refractive index detector and UV-vis DAD was used, the mobile phase being used a solution of $0.05 \mathrm{M}$ $\mathrm{H} 2 \mathrm{SO} 4$; prepared with ultra pure water (Milli-Q) and eluent flow of $0.6 \mathrm{ml} \mathrm{min}^{-1}$. A Aminex HPX-87H $\left(300 \mathrm{~mm} \times 7.8 \mathrm{~mm}\right.$ ) column was used at $30^{\circ} \mathrm{C}$ and the volume of sample injected was $15 \mu \mathrm{l}$ and the total analysis time was set at $30 \mathrm{~min}$.

\subsection{Alkaline peroxide hydrogen pretreatment}

A full factorial design $3^{(2-0)}$ was carried out with 9 runs and two repetitions at the central point, totalizing 11 trials, and study variables were: Temperature $\left({ }^{\circ} \mathrm{C}\right)$ and peroxide concentration $(\%)$. The pretreatment was performed with $10 \%$ dry matter (DM). A hydrogen peroxide solution was prepared by dissolving $\mathrm{H}_{2} \mathrm{O}_{2}$ (4-10\%) in $100.0 \mathrm{~mL}$ of distilled water and adjusting the $\mathrm{pH}$ to 11.5 with sodium hydroxide. The flasks were incubated in an orbital shaker agitated at $150 \mathrm{rpm}$, for $1 \mathrm{~h}$ in the temperature of study. At the end of the reaction time, the material treated was washed until neutral $\mathrm{pH}$, was dried at $30^{\circ} \mathrm{C}$ for $48 \mathrm{~h}$ to obtain a moisture final of $10 \%$. According to the experimental design carried out, the best pretreatment condition was $4 \%$ peroxide, at $60^{\circ} \mathrm{C}$ for 60 minutes and $10 \%$ of solids and was used to prepare the hydrolysates for fermentation step.

\subsection{Enzymatic hydrolysis}

Enzymatic hydrolysis of the pretreated bagasse in the best sugar release condition (10\% solids, $4 \%$ peroxide at $\left.60^{\circ} \mathrm{C}\right)$ was performed at $3 \%(\mathrm{w} / \mathrm{v})$ solids in sodium citrate buffer at $\mathrm{pH} 4.8$ to $50 \mathrm{mM}$. Celluclast 1.5L from Trichoderma reesei (Sigma, USA, Novozyme) was added at a concentration corresponding to $15 \mathrm{FPU} / \mathrm{g}$ biomass in Erlenmeyer flasks of $250 \mathrm{~mL}$, incubated at $150 \mathrm{rpm}$ and $50^{\circ} \mathrm{C}$. The hydrolysates obtained after 72 hours were analysed, for glucose content release and used for fermentation step. The enzymatic loading was based on the study of Gomez-Rueda [17] and Oliveira [2]. After hydrolysis the material was centrifuged at $5000 \mathrm{rpm}$ for 20 minutes and sterilized with a sterile filtration system using Minikap HF Filter MK2M-512-V6S model with a pore diameter of 0.2 $\mu \mathrm{m}$, and a filtration area of $500 \mathrm{~cm}^{2}$ (Spectrum Laboratories, Inc., FL, USA).

\subsection{Fermentation of hydrolysates}

Saccharomyces cerevisiae applied from an unclassified strain cultivated in the food hygiene and bioprocess laboratory at University of Pará and obtained from the Faculty of Food Engineering/ State University of Campinas, originally coming from an industrial ethanol distillery. A unique cell propagation of Saccharomyces cerevisiae was used for all ethanol fermentations. The stock culture maintained at $-20{ }^{\circ} \mathrm{C}$ on a malt agar slant was activated in a liquid medium composed by malt extract $\left(3 \mathrm{~g} . \mathrm{L}^{-1}\right)$ (yeast extract $\left(10 \mathrm{~g} . \mathrm{L}^{-1}\right)$, peptone $\left(5 \mathrm{~g} . \mathrm{L}^{-1}\right)$, Glucose $\left(10 \mathrm{~g} . \mathrm{L}^{-1}\right)$ and distilled water (up to $\left.1 \mathrm{~L}\right)$ and inoculum was grown aerobically in flasks of $250 \mathrm{ml}$ under $150 \mathrm{rpm}$ at $30^{\circ} \mathrm{C}$ for $24 \mathrm{~h}$. The liquid media consisted of sucrose $\left(10\right.$ g.L $\left.\mathrm{L}^{-1}\right)$, Yeast Extract $\left(5\right.$ g.L $\left.\mathrm{L}^{-1}\right), \mathrm{K}_{2} \mathrm{HPO}_{4}\left(5 \mathrm{~g} . \mathrm{L}^{-1}\right), \mathrm{NH} 4 \mathrm{Cl}\left(1.5 \mathrm{~g} . \mathrm{L}^{-1}\right), \mathrm{KCl}(1.15$ g.L. $\left.\mathrm{L}^{-1}\right)$ and $\mathrm{MgSO}_{4} .7 \mathrm{H}_{2} \mathrm{O}\left(0.6510 \mathrm{~g} . \mathrm{L}^{-1}\right)$ and distilled water. Six percent of inoculum (solid fraction postcentrifuged) was used for the fermentation of ASW. The hydrolysates obtained were transferred to flaks of $250 \mathrm{~mL}$, each one with $100 \mathrm{~mL}$ of sterilized hydrolysates. The Erlenmeyer flasks were added with $50 \mathrm{~mL}$ of inoculum and incubated for $24 \mathrm{~h}$ at $34^{\circ} \mathrm{C}$ and $150 \mathrm{rpm}$. The collected aliquots were centrifuged at $4000 \mathrm{rpm}$ for 15 minutes and ethanol contents were analysed. The same procedure was performed for the fermentation in a glass reactor/fermenter (Marconi, model -MA502/D, Brazil). 


\subsection{Statistical analysis}

The results (mean \pm standard deviation) were analysed by Statistica 7.0 software (Statsoft Inc.) using analysis of variance (ANOVA) and Tukey test ( $\mathrm{p}<0.05)$. The best glucose released conditions obtained by RSM were analysed with the same software. Regression coefficients were obtained for the experimental data by fitting to a quadratic model. The model adequacy was determined by evaluating lack of fit, coefficient of determination $\left(\mathrm{R}^{2}\right)$ and Fisher test value (F-value) obtained from analysis of variance (ANOVA).

\section{RESULTS AND DISCUSSION}

\subsection{Chemical composition of açaí seeds}

The seed was composed mainly of cellulose $(40.3 \% \pm 1.30)$, total lignin $(18.3 \% \pm 0.50)$, hemicellulose $(16.2 \% \pm 0.50)$, Extractives $(8.5 \% \pm 0.20)$, Protein $(3.9 \% \pm 1.10)$ and Acetil groups $(4.11 \% \pm 0.80)$. The resulting values of cellulose, lignin and hemicellulose are close to the values obtained by Oliveira et al. [12], which obtained $45.3 \%$ of cellulose and 18.2 of hemicellulose. Others studies describe açaí seeds as biomass consisting of cellulose $(44-47 \%)$ and hemicellulose $(12-19 \%)$ [2,18,19]. RodríguezZúñinga et al. [20] observed values of cellulose (53.2\%); total lignin (22.3\%) and hemicellulose $(12.26 \%)$. The proportion of some compounds for example fibers in the pulp may vary with Euterpe species, modifying chemical composition of the seeds [21]. According to Kim et al. [22], the high content of carbohydrates such as that obtained for the açaí stone would justify its use in the production of ethanol.

\subsection{Pretreatment}

The 11 pre-treatment trials (Table 1) to obtain the best biomass pretreatment condition showed similar yield results with a mean of $79.60 \%$. The run $\mathrm{n}^{\circ} 9$ provided the lowest mass yield, with a value of $75.29 \%$, which shows greater effectiveness in the removal of the lignin present in the biomass; however, it may also be indicative of cellulose loss, since the pretreatment used, $10 \% \mathrm{H}_{2} \mathrm{O}_{2}$ at $65^{\circ} \mathrm{C}$, was more intense than others.

It is also possible to notice that the run 8 despite using a lower concentration of hydrogen peroxide, which was $7 \%$ allowed values of loss of mass of $22.20 \%$ and consequently loss of lignin very close to those obtained in run 9 that used $10 \%$ peroxide at the same temperature. It is a pre-treatment condition to be evaluated more carefully during the enzymatic hydrolysis tests, since lower temperatures are desirable due to the lower energy cost in a possible scale-up scenario.

Therefore, the study condition used in run 7 was chosen as the best because it removed approximately the same amount of lignin observed in run 9 using a smaller amount of $\mathrm{H}_{2} \mathrm{O}_{2}(4 \%)$.

Table 1 - Pretreatment yield and released glucose (experimental design)

\begin{tabular}{lcccc}
\hline Run $\mathrm{N}^{\mathrm{o}}$ & $\mathrm{H}_{2} \mathrm{O}_{2}$ Concentration (W/V\%) & Temperature $\left({ }^{\circ} \mathrm{C}\right)$ & $\begin{array}{c}\text { Solid recovery g.100 g } \\
\text { untreated material }\end{array}$ & $\begin{array}{c}\text { g of glucose/ } \\
\text { 100g de açaí } \\
\text { seeds }\end{array}$ \\
\hline Untreated & - & - & & 1.78 \\
\hline 1 & 4 & 25 & 87.80 & 4.36 \\
2 & 7 & 25 & 85.30 & 3.78 \\
3 & 10 & 25 & 83.10 & 3.62 \\
4 & 4 & 42.5 & 93.60 & 2.55 \\
5 & 7 & 42.5 & 85.50 & 4.34 \\
6 & 10 & 42.5 & 80.50 & 4.62 \\
7 & 4 & 60 & 79.20 & 5.95 \\
8 & 7 & 60 & 77.80 & 5.63 \\
9 & 10 & 60 & 75.29 & 5.17 \\
10 & 7 & 42.5 & 85.10 & 4.13 \\
11 & 7 & 42.5 & 84.20 & 4.39 \\
\hline
\end{tabular}

The highest yield of glucose in the enzymatic hydrolysis was $5.95 \mathrm{~g} . \mathrm{L}^{-1}$ for the condition using $4 \%$ peroxide at $60^{\circ} \mathrm{C}$, and was the best condition for the release of glucose. However, the glucose contents 
released for the non-pretreated material was $1.78 \mathrm{~g} . \mathrm{L}^{-1}, 3.35$ times lower when compared to the best glucose release condition (run $\mathrm{n}^{\circ} 7$ ). Pretreatment provided a maximum increase of $234.26 \%$ in the glucose values released in enzymatic hydrolysis in relation to the glucose values released for the untreated material and show the great how pretreatment is important to produce sugars for ethanol production from biomass lignocellulosic.

\subsection{Statistical analysis of results}

A total of 11 runs was carried out with each run performed in duplicate. For each run, experimental responses are shown in Table 1, which includes glucose release yield in liquid hydrolysate and Solid recovery after pretreatment applied.

According to the Figure 1, the variable Temperature (L) was that showed the highest estimated effect value with positive effect, which is indicative that the higher the temperature in the pre-treatment process, the higher the sugar values released, which is already expected, since the temperature influences directly on the agitation of molecules, improving the encounter between solute and solvent. On the other hand, the peroxide $(\mathrm{L})$ and $(\mathrm{Q})$ concentration variables were not significant. The peroxide concentration (L) showed a positive value, indicating that increases in peroxide concentration values would lead to higher levels of released sugars, which can be justified by the fact that higher $\mathrm{H}_{2} \mathrm{O}_{2}$ contents, should remove lignin content with higher efficiency, allowing a better access of the hydrolytic enzymes and consequent higher sugar released.

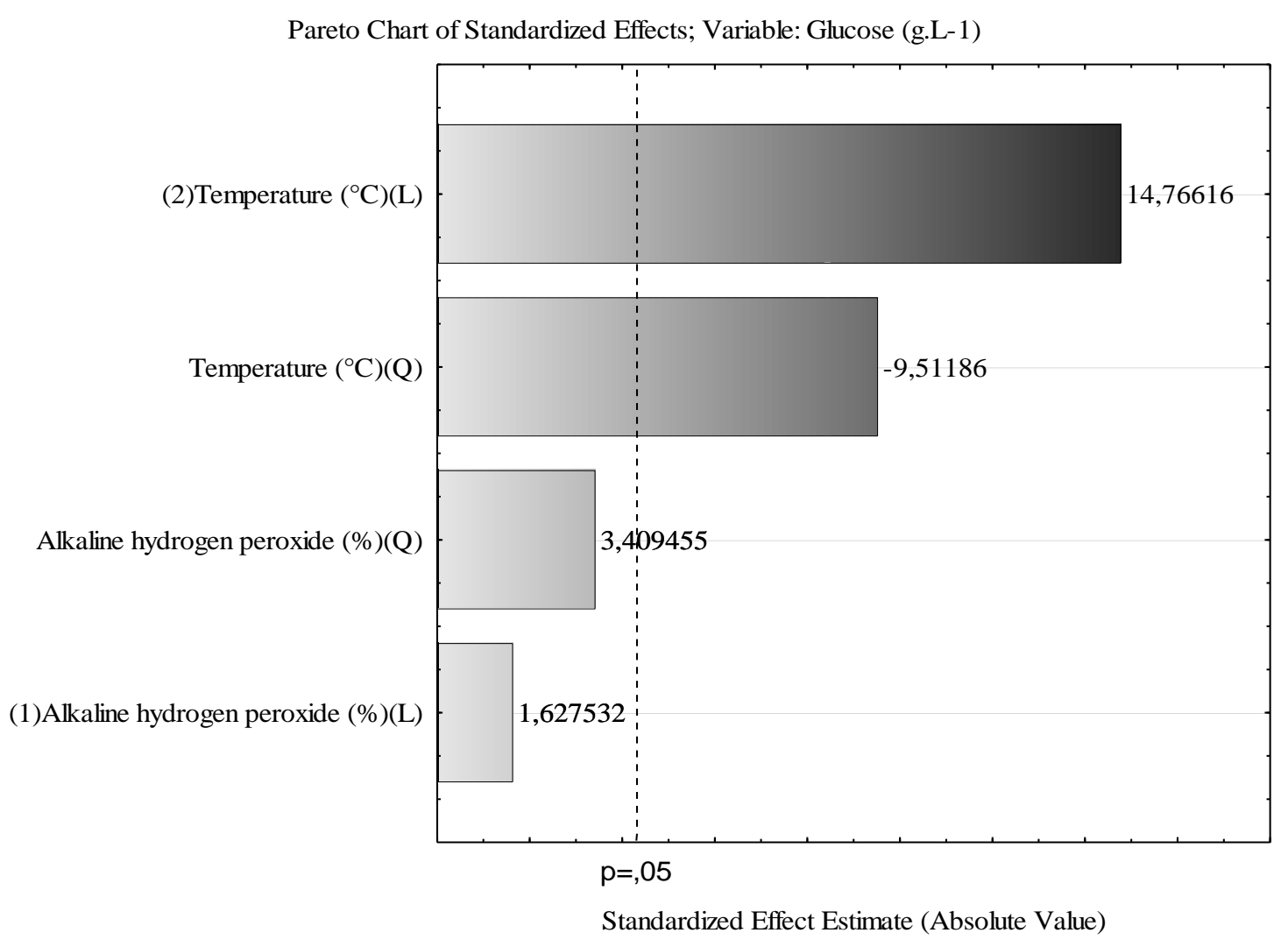

Figure 1- Pareto Charts for the effects of each variable on the pretreatment with Alkaline peroxide hydrogen

ANOVA for the glucose release yield is summarized in Table 2. Was verified that the generated model was not significant, indicating that the generated model was not predictive, since the model did not pass the F-test of the regression, since the value of the F calculated was not at least 5 times greater than the value of $F$ tabled and also did not pass the F-test of the lack of fit, since the F calculated was not less than the F tabled. 
Table 2- Analysis of variance (ANOVA) for the glucose concentration released after the hydrolysis of açaí bagasse pretreated with $\mathrm{H}_{2} \mathrm{O}_{2}$

\begin{tabular}{|c|c|c|c|c|c|}
\hline \multirow[t]{2}{*}{ Source of variation } & \multirow{2}{*}{$\begin{array}{l}\text { Sums of } \\
\text { squares }\end{array}$} & \multirow{2}{*}{$\begin{array}{l}\text { Degree of } \\
\text { freedom }\end{array}$} & \multirow{2}{*}{$\begin{array}{l}\text { Average } \\
\text { Square }\end{array}$} & \multicolumn{2}{|c|}{ F-test $(95 \%)$} \\
\hline & & & & F table & F calculated \\
\hline Regression & 5.94 & 4 & 1.48 & 2.86 & 4.53 \\
\hline Residual & 3.11 & 6 & 0.52 & & \\
\hline Lack of fit & 3.072253 & 4 & 0.768063 & 40.35 & 19.25 \\
\hline Pure error & 0.038067 & 2 & 0.019033 & & \\
\hline Total & 9.048418 & 10 & & & \\
\hline \multicolumn{2}{|l|}{$\%$ of variation explained $\left(\mathrm{R}^{2}\right)$} & & \multicolumn{2}{|c|}{$65.63 \%$} & \\
\hline $\begin{array}{l}\% \text { of maximum explainabl } \\
\text { variation }\end{array}$ & & & & & \\
\hline
\end{tabular}

Therefore, the model or response surfaces could not be generated because of the lack of significant adjustment in the experimental design. The value of $\mathrm{R}^{2}$ was of 0.6563 which shows that the model explained $65.63 \%$ of the variation of the experimental data, which is not desirable, since $\mathrm{R}^{2}$ should result in at least $80 \%$.

\subsection{Fermentation}

After liquefaction and saccharification, sugars were converted to ethanol by $S$. cerevisiae. The hydrolysates obtained and used for fermentation step showed glucose yields of 5,91 g.L $\mathrm{L}^{-1}$ (in erlemmeyers flasks) and 5,96 g.L. (in reactor/fermenter) and ethanol yields produced of 2,41 g.L. $\mathrm{L}^{-1}$ and 2,69 g.L. ${ }^{-1}$, representing $80.15 \%$ and $88,61 \%$ of max theorical yield, respectively. The volumetric ethanol production rate was 0.10 and $0.11 \mathrm{~g} . \mathrm{L}^{-1} \cdot \mathrm{h}^{-1}$ for fermentation carried out in flask and in reactor. The yields of glucose and ethanol were lower than values of 45.50 and $53.04 \mathrm{~g}$ of glucose. $\mathrm{L}^{-1}$, and 21.65 and 15.23g de ethanol. $\mathrm{L}^{-1}$ observed by Oliveira [2] for açaí seeds. Oliveira et al. [23] obtained ethanol yields of $23.12 \mathrm{~g} . \mathrm{L}^{-1}$ for pupunha peels waste. This condition could be result of different treatments used for the authors.

Food waste in general is an organic waste rich in sugars of different forms (polysaccharide, disaccharide, and monosaccharide), some of this sugars can be more easily fermented by yeasts than others, for example when comparing glucose with xylose. In addition, the concentrations of furan compounds formed could inhibit fermentation, leading to lower ethanol concentrations, which was not evaluated in this study. It was possible to verify that the ethanol contents in the reactor were slightly higher than those observed in erlenmeyer explained by the existence of an internal stirring mechanism in the reactor, which would improve the molecules encounter in the reaction and consequently increase the fermentation.

\section{CONClusions}

The treatment with alkaline hydrogen peroxide is a promising pretreatment in lignin removal and consequently facilitates the enzymatic hydrolysis process in the production of ethanol; however, the ethanol contents produced need adjustments to be improved, however, with a great possibility of expansion of the pretreatment conditions, which could lead to higher levels of ethanol produced.

\section{REFERENCES}

[1] Kohlhepp, G, (2010) Analysis of the state of production of ethanol and biodiesel in Brazil, Advanced Studies, Vol. 24, No. 68, pp 1-31.

[2] Oliveira, J. A. R, (2014) Investigation of the steps for the second generation ethanol production process from the biomass of the açaí seeds (Euterpe oleracea). $\mathrm{PhD}$ thesis in Chemical Engineering - Faculty of Chemical Engineering, State University of Campinas, Campinas-SP. 
[3] Zhang, Y., Yang, J., Luo, L., Wang, E., Wang, R., Liu, L, Yuan, H, (2020) Low-Cost CellulaseHemicellulase Mixture Secreted by Trichoderma harzianum EM0925 with Complete Saccharification Efficacy of Lignocellulose, International Journal of Molecular Sciences, Vol.21, No. 2, pp1- 371.

[4] Wang, J, Chen, X, Chio, C, Yang, C, Su, E, Jin, Y, Cao, F, Qin, W, (2019) Delignification overmatches hemicellulose removal for improving hydrolysis of wheat straw using the enzyme cocktail from Aspergillus niger, Bioresour. Technol, Vol. 274, No.2, pp.459-467.

[5] Yuan, Z, Wen, Y., \& Kapu, N. S, (2018) Ethanol production from bamboo using mild alkaline preextraction followed by alkaline hydrogen peroxide pretreatment, Bioresource Technology, Vol.247, No.10, pp. 242-249.

[6] BRASIL IBGE. (2016) Production of Vegetable Extraction and Forestry from: https://biblioteca.ibge.gov.br/visualizacao/periodicos/74/pevs_2016_v31.pdf

[7] Qing, Q, Zhou, L, Guo, Q, Gao, X, Zhang, Y, He, Y, Zhang, Y, (2017) Mild alkaline presoaking and organosolv pretreatment of corn stover and their impacts on corn stover composition, structure, and digestibility, Bioresour. Technol, Vol. 233, No 13, pp. 284-290.

[8] Del Campo, I, Alegria, I, Zazpe, M, Echeverria, M, Echererria, I, (2006) Diluted acid hydrolysis pretreatment of agri-food wastes for bioethanol production, Industrial Crops and Products, Vol. 24, pp. 214-221.

[9] Lin, Y, Tanaka, S, (2006), Ethanol fermentation from biomass resources: current state and prospects, Applied Microbiology and Biotechnology, Vol. 69, pp.627-642.

[10] Oliveira, J.A.R, Komesu A, Maciel Filho R, (2014) Hydrothermal pretreatment for enhancing enzymatic hydrolysis of seeds of açaí (Euterpe oleracea) and sugar recovery, Chem Eng Trans, Vol, 37, pp.787792.

[11] Alvarez-Vasco, C., Zhang, X, (2017) Alkaline hydrogen peroxide (AHP) pretreatment of softwood: Enhanced enzymatic hydrolysability at low peroxide loadings, Biomass Bioenergy Vol.420, No. 96, pp. 96-102.

[12] Oliveira, J.A.R, Martins, L.H.S, Komesu, A, Maciel Filho, R, (2015) Evaluation of alkaline delignification $(\mathrm{NaOH})$ of açaí seeds (Eutherpe oleracea) treated with $\mathrm{H} 2 \mathrm{SO} 4$ dilute and effect on enzymatic hydrolysis. Chem Eng Trans, Vol. 43, pp.499-504.

[13] Sluiter, A, Hames, B, Ruiz, R, Scarlata, C, Sluiter, J, Templeton, D, (2005) Determination of total Solids in Biomass. National Renewable Energy Laboratory (NREL), pp.1-6.

[14] AOAC. (1997) Official methods of analysis of the Association of Official Analytical Chemists: 16.ed. Washington. v.2, $850 \mathrm{p}$.

[15] Sluiter, A, Ruiz, R, Scarlata, C, Sluiter, J, Templeton, D. (2008) Determination of extractives in biomass (b). National Renewable Energy Laboratory (NREL), pp.1-18.

[16] Dence, C.W. The determination of lignin. In: Lin S.Y, Dence C.W., editors. Methods in Lignin Chemistry. Springer-Verlag; Heidelberg, Germany: 1992. pp. 33-61.

[17] Gomez-Rueda, S. M. (2010) Pretreatment and Enzymatic Hydrolysis of Sugarcane Bagasse. Master's Dissertation - State University of Campinas, Faculty of Chemical Engineering, Campinas-SP. 301p.

[18] Altman, F. F. A, (1956) The acai seeds (Euterpe olaracea Mart.). Belém, Brazil, Instituto Agronômico. Technical Bulletin No. 31, pp.12-24.

[19] Rodrigues Filho J.A, Camarão AP, Lourenço Júnior JB (1993) Avaliação de subprodutos agroindustriais para a alimentação de ruminantes. EMBRAPA-CPATU, Belém, p 15.

[20] Rodríguez-Zúñiga, U. F, Lemo, V., Farinas, C. S, Bertucci Neto., Couri, S. (2008) Evaluation of agroindustrial waste as substrates for cellulolytic enzymes production under solid state fermentation. In: Encontro da Sociedade Brasileira de Pesquisa em Materiais - SBPMat, 7, Guarujá; BRAZILIAN MRS MEETING, Guarujá. Abstracts. Rio de Janeiro: SBPMat.

[21] Yamaguchi, K.K.D.L, Pereira, L.F.R, Lamarão. C.V, Lima, E.S, da VeigaJunior, V.F, (2015) Amazon acai: chemistry and biological activities: a review, Food Chem, No.179, pp.137-151.

[22] KIM, S. HOLTZAPPLE, M.T, (2005) Lime pretreatment and enzymatic hydrolysis of corn stover, Bioresour. Technol, No. 96, pp. 1994-2006. 
[23] Oliveira, J.A.R, Oliveira, L.S, Cassiano, K.S, (2020) Enzymatic hydrolysis of pupunha shell for second generation ethanol production, Brazilian Journal of development (Accepted for publication).

\section{AUTHORS}

Adriene Carvalho da Conceição: She received the B.S degree in 2018 (Federal University of Pará, Brazil).

Marcele Fonseca Passos: is Professor in Department of Biotechnology, Federal University of Pará, Brazil. He received the B.S. degree in 2008 (Technology in Polymerization Processes at Federal Centre for Technological Education of Bahia, Brazil), the M.S. degree in 2011 (Chemical engineering at University of Campinas, Brazil) and Ph.D. degree in 2016 (Chemical engineering, University of Campinas, Brazil).
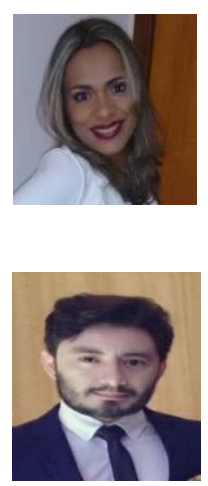

Johnatt Allan Rocha de Oliveira: is Professor in Department of nutrition, Federal University of Pará, Brazil. He received the B.S. degree in 2007 (Food Technology at Federal University of State of Pará, Brazil), the M.S. degree in 2009 (Food Science and Technology at Federal University of Pará, Brazil) and Ph.D. degree in 2015 (Chemical engineering, University of Campinas, Brazil). 